\title{
Erratum to: Food supply chains: coordination governance and other shaping forces
}

Anna Carbone

Correspondence: acarbone@unitus.it Dibaf, Università della Tuscia, via san Camillo de Lellis snc, 01100 Viterbo, Italy

\section{Erratum}

In the original publication [1] were some errors in the abstract. The correct part can be found here:

(iii) supply chains populated by reciprocal and pooled relationships and ruled by a more relational kind of governance, beside potentially bringing advantages in terms of decision power and economic benefits, also raise difficulties and drawbacks due to complexity of functioning, heterogeneity of stakeholders, and ambiguity of the nature of relations among them.

Received: 16 March 2017 Accepted: 16 March 2017

Published online: 27 March 2017

\section{Reference}

1. Food supply chains: coordination governance and other shaping forces (2017). Agric Food Econ. 5:3 doi:10.1186/s40100-017-0071-3 